\title{
REVIEW
}

\section{CLINICAL RELEVANCE OF P-GLYCOPROTEIN EXPRESSION IN HAEMATOLOGICAL MALIGNANCIES}

\author{
K. NOOTER* and P. SONNEVELD $\dagger$ \\ ${ }^{*}$ Department of Medical Oncology, Rotterdam Cancer Institute, Rotterdam, The Netherlands; and \\ $†$ Department of Haematology, University Hospital Dijkzigt, Rotterdam, The Netherlands
}

(Received 25 October 1993. Accepted 6 November 1993)

\begin{abstract}
Although, generally speaking, haematological malignancies are chemotherapyresponsive tumours and high remission induction rates are obtained, disease-related death is the rule rather than the exception. The appearance of cell populations, resistant to multidrugbased chemotherapy, constitutes the major problem to achieve cures in these patients. Advances in cell biology have partly contributed to the elucidation of different multidrug resistance (MDR) mechanisms, which enable cells to survive the cytotoxic effects of multiple chemotherapeutic agents. Of these resistance mechanisms, the one that is referred to as classical MDR is the most extensively studied, both in the laboratory as well as in patients, and here we will focus on its clinical relevance in haematological malignancies. The classical MDR phenotype is caused by enhanced cellular drug efflux due to increased activity of a membrane-bound glycoprotein (P. glycoprotein) drug pump, that can pump out anthracyclines, anthracenediones, vinca alkaloids and epipodophyllotoxins, thereby actively lowering the intracellular drug concentrations to sublethal levels. As soon as molecular probes for the detection of MDR cells became available, clinical studies were initiated to answer three main questions. Do human tumour cells express P-glycoprotein? If so, is the expression indicative of a bad prognosis, c.q. resistant disease? And last but not least, can we interfere with the P-glycoprotein drug pump in the patient? Clinical data indicate that classical MDR may be involved in the development of drug resistance, especially in some haematological malignancies, such as acute myelocytic leukaemia (AML), non-Hodgkin's lymphomas (NHL), and multiple myelomas (MM). In almost all types of haematological malignancies, either untreated or treated, elevated P-glycoprotein levels have been reported, ranging from low to high. However, the acquisition of clinical MDR associated with P-glycoprotein expression occurs only in those diseases (for example, AML and MM) that are heavily treated with MDR-related drugs, probably by selection of pre-existing P-glycoprotein-expressing malignant cells. Since P-glycoprotein is found to be expressed on the membrane of normal haemopoietic progenitor cells as well, it seems likely that P-glycoprotein-positive haematological tumours develop by malignant transformation of P-glycoprotein-expressing normal haemopoietic counterparts. Especially for AML, convincing data have been reported in the literature to show that $\mathrm{P}$-glycoprotein expression at diagnosis is a bad prognostic factor that predicts refractoriness. Using in vitro model systems for classical MDR, a large number of agents have been identified that can circumvent P-glycoprotein-mediated drug resistance, the so-called resistance modifying agents (RMA). Subsequently, clinical phase I and II studies have been initiated which combine the use of MDR-related drugs in conjunction with RMAs. The overall conclusions from such studies in AML, NHL, and MM are that modulation of drug resistance by RMAs seems promising and that further evaluation in prospective, randomized phase lll trials is warranted.
\end{abstract}

Key words: Multidrug resistance, MDR, P-glycoprotein, clinical relevance, haematological malignancies, circumvention of MDR, clinical trials.

\section{Introduction}

CHEMOTHERAPY FAILURE owing to cellular drug resistance remains a major problem in most patients suffering from leukaemia, lymphoma or multiple myeloma. After an initial response, a relapse often follows that neither responds to the drugs initially used, nor to a variety of other anticancer drugs. Laboratory investigations have now provided a cellular basis for this clinically defined phenomenon of pleiotropic drug resistance. Selection of cells in vitro for resistance to a 'naturally occurring' anticancer 
drug, results in the development of cross-resistance to other, structurally unrelated drugs. Several human cell lines displaying such a multidrug resistance (MDR) phenotype have been identified, and so far three separate forms of MDR have been characterized in more detail: classical MDR, atypical MDR, and non-Pgp MDR. The classical MDR phenotype is caused by enhanced cellular drug efflux due to increased activity of a membrane-bound glycoprotein (P-glycoprotein) drug pump, that can pump out anthracyclines, anthracenediones, vinca alkaloids and epipodophyllotoxins, thereby actively lowering the intracellular drug concentrations to sublethal levels (for reviews on MDR, see refs [1 and 2]). A second form of pleiotropic drug resistance (atypical MDR) is associated with quantitative or qualitative alterations in topoisomerase II, a nuclear enzyme that actively participates in the lethal action of cytotoxic drugs [3]. Characteristically, there is cross-resistance to the full range of drugs that interact with the enzyme, among which are acridines, anthracyclines, anthracenediones, ellipticines and epipodophyllotoxins, but not to the vinca alkaloids. The anti-topoisomerase II drugs are thought to exert their cytotoxic effects by formation of a stable ternary DNA-topoisomerase II drug complex. Because of the altered cross-resistance pattern, as compared with the classical MDR phenotype, this form of drug resistance is referred to either as atypical MDR, or as altered topoisomerase II MDR (at-MDR), to denote the essential role of topoisomerase II in this form of drug resistance. Atypical MDR cells do not overexpress P-glycoprotein, and are unaltered in their ability to accumulate drugs (for a review on atypical MDR, see ref. [4]). Although atypical MDR is potentially of clinical importance, the question whether the phenomenon contributes to clinical drug resistance in haematological malignancies cannot be answered yet, because so far only very limited data are available on the expression of topoisomerase II in human tumour specimens [5-7]. The third form of MDR (non-Pgp MDR) strongly

Abbreviations: $A L L$, acute lymphocytic leukaemia; $A M L$, acute myelocytic leukaemia; $A U C$, area under the curve; $B M$, bone marrow; $C L L$, chronic lymphocytic leukaemia; $C M L$, chronic myelocytic leukaemia; $C R$, complete remission; $M D R$, multidrug resistance; $M D S$, myelodysplastic syndrome; $M M$, multiple myeloma; $M o A b$, monoclonal antibody; $N H L$, non-Hodgkin's lymphoma; $P B$, peripheral blood; $R D$, resistant disease; $R I$, remission induction; $R M A$, resistance modifying agent; $V A D$, vincristine, doxorubicin, dexamethasone.

Correspondence to: K. Nooter, Dept. Medical Oncology. Rotterdam Cancer Institute/AZR, Dr. Molewaterplain 40, 3015 GD Rotterdam. The Netherlands (Tel: +31 10 4633831 ; Fax: +31104633268 ). resembles the classical MDR phenotype, as far as cross-resistance patterns are concerned, however, without expression of the P-glycoprotein molecule; hence the name non-Pgp-mediated MDR. Presumably there are different forms of non-Pgp MDR. In most non-Pgp MDR cells lines intracellular drug accumulation is reduced owing to energy-dependent, enhanced drug efflux [8-14], as in classical MDR. Recently, a new putative transmembrane drug transporter, called MDR-related protein (MRP) [15], has been identified in a non-Pgp MDR cell line that does not exhibit reduced intracellular drug accumulation [16] as the possible cause of drug resistance. However, MRP is found to be overexpressed in other non-Pgp MDR cell lines as well, irrespective of reduced intracellular drug accumulation [17]. Clearly, much work has to be done before the precise mechanisms underlying non-Pgp MDR and the nature of the gene(s) affected are known. Of the above mentioned pleiotropic drug resistance phenotypes, the classical one is the most extensively studied, both in the laboratory and in cancer patients. Here we will restrict ourselves to review some clinical aspects of classical MDR. Since recent data indicate that classical MDR may be involved in the development of clinical drug resistance (for a review on the clinical relevance of MDR, see ref. [18]), especially in some haematological malignancies, we will focus on these diseases.

As mentioned earlier, the classical MDR phenotype is characterized by a reduced ability to accumulate drugs, as compared with the parent cell lines, being most likely the main cause of multidrug resistance. This reduced drug accumulation is due to activity of an energy-dependent unidirectional drug efflux pump wih broad substrate specificity. The MDR drug pump is composed of a transmembrane glycoprotein (P-glycoprotein) with a molecular weight of $170 \mathrm{kDa}$, encoded by the so-called $m d r$ genes, and uses energy in the form of ATP to transport drugs through a channel formed by the transmembrane segments. In humans, two P-glycoprotein isoforms ( $m d r l$ and $m d r 3$ ) have been identified $[19,20]$, of which, in transfection experiments, only the $m d r l$ gene product (referred to as P-glycoprotein) confers drug resistance $[21,22]$. In classical MDR cells, selection for resistance to 'naturally occurring' drugs, for example, anthracyclines, vinca alkaloids, podophyllotoxins, and colchicine, results in the development of cross-resistance to other members of the MDR drug family. These MDR-related drugs are structurally dissimilar and have different intracellular targets. What these drugs have in common is that they are, in general, rather large (between 300 and $900 \mathrm{MW}$ ), hydrophobic, enter the cell by passive diffusion, and have affinity for 
P-glycoprotein. Classical MDR cells are not crossresistant to alkylating agents (e.g. chlorambucil and cyclophosphamide), antimetabolites (for example, cytarabine, methotrexate and 5-fluorouracil), or cisplatin.

P-glycoprotein appeared to be a normal membrane constituent in certain cell types, and expression is not only found in drug resistant in vitro cell lines but also in normal tissues with excretory functions like liver, kidneys, and colon [23], suggesting that it plays a role in the process of detoxification of the organism. However, P-glycoprotein is also clearly expressed in the adrenal glands, in the endometrium of the gravid uterus and in the human placental trophoblast, indicating that the molecule has a normal physiological function, e.g. in steroid hormone transport. Over the years, a large number of other non-cytotoxic compounds, including calcium channel blockers and calmodulin inhibitors, has been found, which can also serve as substrates for the P-glycoprotein drug pump, and thereby circumvent drug resistance. The current hypothesis on the mode of action of these socalled resistance modifying agents (RMA) is that they correct the defect cytotoxic drug accumulation in MDR cells by competing for outward transport directly by binding with P-glycoprotein [24], although it must be emphasized that the unusually broad substrate specificity of P-glycoprotein still constitutes an academic problem.

It is a very likely (and testable) hypothesis that the clinical observation of resistance to multidrug-based chemotherapy of haematological malignancies is due to enhanced P-glycoprotein expression in the resistant cells. MDR-related cytotoxic drugs (anthracyclines, vinca alkaloids, and podophyllotoxins) are among the most active agents in the treatment of haematological malignancies. In these cancers, a relapse of resistant disease is frequently followed after a period of complete remission (CR).

\section{P-glycoprotein expression in haematological malignancies}

Elevated P-glycoprotein levels and/or $m d r l / P$ glycoprotein mRNA transcript levels have been reported in almost all types of haematological malignancies, either untreated or treated, with expression levels ranging from low to high. A variety of different techniques have been used in the studies on the expression of P-glycoprotein and its mRNA in human haemopoietic neoplasms, all with their specific advantages and disadvantages [25]. Several monoclonal antibodies (MoAb) directed against P-glycoprotein epitopes and P-glycoprotein-specific nucleic acid probes are available, respectively, for immunocytochemistry and Western blotting for the detection of the protein, and Northern- and slot blotting, RNase protection and polymerase chain reaction for the detection of its mRNA. All these techniques have been worked out using in vitro MDR model systems with abundant P-glycoprotein expression. In contrast, relatively low expression levels might be anticipated, and are actually found in clinical samples, a fact that beyond doubt has contributed to contradictory findings in the literature. Another point of consideration is the specificity of the probes for the detection of P-glycoprotein or its mRNA. As alluded to earlier, in humans two $m d r$ genes ( $m d r 1$ and $m d r 3$ ) with a high degree of homology have been identified, each coding for a glycoprotein [22]. Using $m d r l$ - and $m d r 3$-specific nucleic acid probes we have found that the $m d r 3$ gene is specifically expressed in B-cell leukaemias and lymphomas [26-29]. Since not all MoAbs used in studies on P-glycoprotein expression in clinical samples are specific for the P-glycoprotein encoded by the $m d r l$ gene (for example, the MoAb C219), and for some nucleic acid probes it has not been documented whether they are $m d r l / \mathrm{P}$-glycoprotein mRNAspecific, it is theoretically possible that in B-cell leukaemias and lymphomas, P-glycoprotein expression levels have been overestimated, because of the lack of specificity.

Ma et al. [30] were the first who reported P-glycoprotein expression in two adult patients with acute myelocytic leukaemia (AML) by immunocytochemical assay using the MoAb C219, developed by Ling's group. P-glycoprotein staining could not be detected in the leukaemic cells at first clinical admission. However, as the patients relapsed after three or four courses of combined chemotherapy containing daunorubicin, C219 positive leukaemic cells appeared in the peripheral blood (PB). The proportion of positive staining cells and the intensity of staining increased as the disease progressed. The study of Ma et al. [30] had been initiated by Bell et $a l$, who had successfully applied the same MoAb earlier in an ovarian carcinoma study [31], and ushered in a period of large scale screening for P-glycoprotein expression in all kinds of haematological malignancies. Reports appeared on elevated P-glycoprotein or $m d r l / P$-glycoprotein mRNA levels in AML [27, 32-34], acute lymphocytic leukaemia (ALL) $[27,32,35,36]$, myelodysplastic syndromes (MDS) [33], chronic myelocytic leukaemia (CML) $[27,32,37]$, chronic lymphocytic leukaemia (CLL) $[26,38,39]$, hairy cell leukaemia [28], multiple myeloma (MM) [40-42], non-Hodgkin's lymphomas (NHL) [43-45], as detected by immunocytochemistry, slot blot analysis, or RNase protection assay. 
From the studies that used in situ methods (immunocytochemistry or in situ RNA hybridization) for the detection of P-glycoprotein expression, it became apparent that the leukaemic cell population can be very heterogeneous, with several distinct populations expressing high, moderate, or no P-glycoprotein expression, clearly demonstrating a limitation of the assays on RNA isolated from the total leukaemic cell population. The clinical implication of the heterogeneity in P-glycoprotein expression in the tumour cell population would be selection of the Pglycoprotein-expressing cell clones following treatment with MDR-related drugs. Indeed, evidence for selection of pre-existing MDR clones can be found in those malignancies for which the standard protocols contain MDR-related drugs, in, for example, adult AML. Although elevated P-glycoprotein expression levels are frequently observed in AML at diagnosis, the expression in treated AML patients with resistant disease (RD) is generally higher, as quantitated by analyis of RNA isolated from the total leukaemic cell population $[27,46-48]$ as well as at the single cell level by immunocytochemistry $[30,48]$. Comparable evidence for selection has also been provided for MM: higher incidence of P-glycoprotein expression in patients treated with the VAD (vincristine, doxorubicin, dexamethasone)-protocol than in patients at initial presentation [49]. In the study by Grogan et al. [49] about a hundred MM patients were analysed, either before or after therapy and at the time of relapse. MM patients with no prior therapy had low incidence $(6 \%)$ of P-glycoprotein expression, while those receiving chemotherapy with doxorubicin and/or vincristine had a significant higher incidence that was related to the cumulative drug dosages, and that finally became $100 \%$ at the highest cumulative drug levels. Typically, in a disease like CLL no clear evidence for selection can be found. Variable degrees of P-glycoprotein expression are observed in CLL at diagnosis, however, after the conventional treatment with an alkylator, with or without prednisone, agents that do not belong to the MDR drug family, Pglycoprotein expression levels appeared not to be related to prior therapy [27, 39].

Apart from selection of the MDR phenotype by repeated chemotherapeutic treatment, it remains possible that chemotherapeutic agents might themselves directly induce P-glycoprotein expression at the transcriptional level. Evidence is accumulating that, at least in vitro in rodent and human cell lines, the $m d r 1 /$ P-glyccprotein promoter can be activated by chemical stress-inducing agents, including cytotoxic and cytostatic drugs, like vincristine, etoposide, daunorubicin, doxorubicin, colchicine, and hydroxyurea [50-52]. If such a chemical activation of the $m d r 1 / \mathrm{P}$-glycoprotein promotor also occurs in the patient, that would also result in increased P-glycoprotein expression in the leukaemic cell population after chemotherapy; a situation that is hardly discernible from in vivo selection.

\section{Origin of the MDR phenotype}

Recent studies [53-55] have shown that P-glycoprotein is differentially expressed among the diverse haemopoietic differentiation lineages. In PB, granulocytes and monocytes were negative for $\mathrm{P}$ glycoprotein, while T-cells, B-cells and NK cells were P-glycoprotein-positive. In bone marrow (BM), erythroid precursors and monocytic cells had no Pglycoprotein expression. The $\mathrm{CD}^{+} 4^{+}$early progenitor cells, committed progenitor cells, myeloid precursor cells, and early and mature B-cells were positive for P-glycoprotein. Consequently, P-glycoprotein expression in untreated haematological malignancies might be determined by the expression in the normal haemopoietic counterparts. A correlation between $\mathrm{P}$-glycoprotein expression and immature $\left(\mathrm{CD}^{2} 4^{+}\right)$cell phenotype has been reported for AML, MDS and therapy-induced AML [48, 5658]. Since normal $\mathrm{CD} 34^{+}$haemopoietic progenitor cells have P-glycoprotein expression [53], it is conceivable that $\mathrm{CD}^{+} 4^{+}$leukaemias develop by malignant transformation of normal $\mathrm{CD} 34^{+}$counterparts. Such a correlation between P-glycoprotein expression and immature cell phenotype was also reported by List et al. [56] and Sonneveld et al. [58] for MDS. In the latter study [58] P-glycoprotein expression was investigated in patients with high-risk $(n=9)$ or low-risk ( $n=17)$ MDS. Patients with highrisk MDS have a poor prognosis owing to a high risk of transformation to AML which is usually resistant to chemotherapy. P-glycoprotein expression was demonstrated in $\mathrm{CD}^{+} 4^{+} \mathrm{BM}$ blast cells in 14 of 17 high-risk MDS and in two of nine low-risk MDS patients. About $80 \%$ of the P-glycoprotein-positive patients developed AML vs $20 \%$ of the P-glycoprotein-negative patients, providing a mechanistic basis for the poor chemotherapy-responsiveness of this form of AML.

Before a normal cell ends up as a tumour cell, it has gone through a (multistage) process of malignant transformation. During such a process of genetic instability, cells gain new characteristics by mutations and/or alterations in gene expression. Recently, it was reported [59] that the promoter of the human $m d r l /$ P-glycoprotein gene can be activated by the $c$ Ha-ras-l oncogene and the p53 tumour suppressor gene products. The stimulatory effect of the ras gene product was not specific to the $m d r l / \mathrm{P}$-glycoprotein 
TABLE 1. P-GLYCOPROTEIN EXPRESSION AS A PROGNOSTIC FACTOR IN DE NOVO AML.

\begin{tabular}{lcccc}
\hline \multicolumn{1}{c}{ Author } & Ref. No. & No. patients & $\begin{array}{c}\text { P-glycoprotein expression } \\
\text { Yes } \\
\text { No } \\
\text { CR }(\%)\end{array}$ & CR $(\%)$ \\
\hline Kuwazuru et al. $(1990)$ & 60 & 15 & 15 & 85 \\
Sato et al. $(1990)$ & 46 & 33 & 60 & 85 \\
Marie et al. $(1991)$ & 47 & 18 & 25 & 85 \\
Pirker et al. $(1991)$ & 61 & 63 & 55 & 90 \\
Campos et al. $(1992)$ & 57 & 122 & 30 & 75 \\
Zhou et al. (1992) & 48 & 61 & 35 & 72 \\
Te Boekhorst et al. $(1993)$ & 62 & 52 & 27 & \\
\hline
\end{tabular}

promoter alone, whereas a mutant $p 53$ specifically stimulated the $m d r l / P$-glycoprotein promoter and wild-type $p 53$ exerted specific repression. Both genes, $p 53$ and ras are frequently associated with tumour progression, and mutations in $p 53$ and members of the ras oncogene family are among the most frequently found genetic aberrations in human neoplasms, including leukaemias. These results imply that P-glycoprotein expression could be activated during tumour progression associated with mutations in ras and $p 53$.

\section{Does P-glycoprotein expression predict resistant disease?}

The answer is: yes, but only for some specific haematological malignancies, for example, AML and MM, diseases which are usually treated with MDRrelated drugs. In these diseases, high levels of Pglycoprotein before treatment appear to be associated with poor prognosis, c.q. resistant disease. In the case of AML the prognostic significance of Pglycoprotein expression is extensively studied and the picture appears to be very clear. Several groups [46-48, 57, 60-62] have investigated the significance of P-glycoprotein overexpression as a prognostic factor in de novo AML (Table 1). The overall conclusion from these AML studies is that P-glycoprotein expression at diagnosis is clearly an unfavourable prognostic factor for lower CR rates, refractory disease, early death, and shorter disease-free survival. In Table 1 , the $C R$ rates are shown in relation to $\mathrm{P}$-glycoprotein expression at diagnosis in de novo AML, reported by the Japanese, American and European clinical haemato-oncology research groups. In all studies the probability of obtaining a CR was dramatically reduced in the presence of $P$ glycoprotein and high P-glycoprotein levels could be correlated with RD. Crucial for such a correlation between CR rate and P-glycoprotein expression is the sensitivity of the assay for P-glycoprotein. False negative results owing to the insensitivity of the method would result in a lower CR rate in both AML groups, with or without P-glycoprotein expression. In the studies listed in Table 1 different techniques have been used for the detection and quantification of P-glycoprotein or its mRNA: immunoblotting with the MoAb C219 [60], Northern blotting [46], slot blot analysis $[47,48,61]$, flow cytometry with the MoAb MRK16 [57,62], or immunocytochemistry with $\mathrm{C} 219$ [48, 62]. The percentage of P-glycoproteinpositive AML samples at diagnosis ranged from 40 to $70 \%$, irrespective of the method used, and except for the $15 \% \mathrm{CR}$ rate in the P-glycoprotein-positive AML group of Kuwazuru et al. [60], more or less identical results have been obtained for the predictive significance of P-glycoprotein. P-glycoprotein expression at diagnosis could not be related to the FAB classification of AML [46, 57]. The two main drugs for remission induction (RI) in de novo standard risk AML are an anthracycline in combination with cytarabine. This drug combination gives an average overall CR rate of $70-80 \%$. With conventional dose ara-C alone $\mathrm{CR}$ rates of $30 \%$ are obtained, a figure that fits within the range of $\mathrm{CR}$ rates obtained in P-glycoprotein-positive AML patients. In the study from Lyon [57] it was reported that elevated levels of P-glycoprotein in leukaemia cells correlated with the presence of CD34 antigen, although both markers independently conferred a negative prognostic value. By combining both markers, CD34 and P-glycoprotein, it was possible to define a subgroup with a very poor prognosis (both markers positive, CR rate: $20 \%$ ) and a subgroup with a very good prognosis (both markers negative, CR rate: 100\%). In a recent study by our own group [62] it was shown by double-fluorescence labelling that $\mathrm{P}$-glycoprotein is indeed almost exclusively expressed in $\mathrm{CD}^{+} 4^{+}$ AML blasts. In secondary AML, preceded by cytotoxic exposure and/or a preleukaemic phase, the prognosis is considerably worse than in de novo AML. In these patients a poor prognosis is also 
associated with increased expression of P-glycoprotein $[33,46,47,56,57,62]$, and with concurrent expression of P-glycoprotein and abnormal karyotype:monosomy 7 and/or $7 q-$, as detected by in situ hybridization [62].

Several groups have published increased expression of $\mathrm{P}$-glycoprotein in $\mathrm{MM}$ during development of clinical drug resistance $[42,49]$. In most centres, the standard first line treatment for $M M$ is melphalan and prednisone which produces an objective response in about $50 \%$ of patients. Patients not responding or relapsing following initial treatment are often treated with combination chemotherapy containing VAD. Linsenmeyer et al. [42] reported that in MM, patients who failed to respond to first line therapy with melphalan and prednisone had significantly higher $m d r l / P$-glycoprotein mRNA levels than patients who responded. Since both drugs do not belong to the MDR drug family, the effectiveness of these drugs would not be expected to be impaired significantly in P-glycoprotein-positive tumours. The explanation for this apparent paradox seems to lie in coordinate increases in expression of other pathways involved in the detoxification of xenobiotics. In the same study [42] other genes (glutathione S-transferase (GST) 2 and 3) potentially of importance in drug resistance were investigated as well, and P-glycoprotein and GST2 expression, an enzyme with the ability to inactivate drugs such as melphalan [63], were significantly correlated. MM patients with no prior therapy had a low $(6 \%)$ incidence of P-glycoprotein expression. However, in many untreated and melphalan/prednisone treated MM patients, small numbers $(<5 \%)$ of P-glycoprotein plasma cells can be detected, as is the case in benign monoclonal gammopathy (MGUS) [64]. It is, therefore, conceivable that selection of P-glycoprotein-expressing myeloma cells occurs during successive treatments. Indeed, the incidence of Pglycoprotein positive patients increased dramatically in $\mathrm{MM}$ after each course of chemotherapy with doxorubicin and/or vincristine [49]. Increased Pglycoprotein expression was observed in $60-80 \%$ of VAD-refractory patients, and in VAD-treated MM patients P-glycoprotein expression appeared to be a bad prognostic factor, predicting for RD $[41,49]$. In summary: in MM, P-glycoprotein expression appears to have no impact on chemotherapy response if it is found before treatment with doxorubicin or vincristine [65], while in VAD-treated patients it predicts for poor response.

In untreated ALL the frequency of elevated P-glycoprotein expression ranged from 10 to $70 \%$ $[27,32,35,36,60,66]$ and a correlation between P-glycoprotein expression and treatment outcome seems to be less outspoken as in AML. Only in a few studies $[36,47,60]$ could P-glycoprotein expression be linked with clinical results. In one study [47] increased P-glycoprotein expression could be detected in $40 \%$ of the ALL patients $(n=7)$, and none of them obtained a CR, vs $75 \%$ of the Pglycoprotein-negative patients. In another study [60] $(n=11), 25 \%$ of the P-glycoprotein-positive ALL patients obtained a CR, vs $65 \%$ of the P-glycoprotein-negative patients. In a recently published study [36], a separation was made between adult ( $n=$ $23)$ and childhood ALL $(n=36)$. The rate of first CR differed between P-glycoprotein-positive and -negative patients in adult ALL only (56\% vs 93\%); in the paediatric patients, P-glycoprotein-positive and -negative patients had exactly the same rate of CR (92\%). Of the 16 P-glycoprotein-positive patients ( 11 children and 5 adults) who presented a first CR, $81 \%$ relapsed, compared with $37 \%$ of the P-glycoprotein-negative patients. A higher rate of relapse among P-glycoprotein-positive compared with P-glycoprotein-negative patients was observed in adults as well as in children (adults $100 \%$ vs $46 \%$; children $73 \%$ vs $32 \%$ ). Also, the survival rates were significantly higher in the P-glycoprotein-negative compared with P-glycoprotein-positive ALL adults and children. These data strongly suggest that in ALL Pglycoprotein might be a poor prognostic factor.

Other leukaemias in which variable degrees of $\mathbf{P}$ glycoprotein expression have been detected at diagnosis include chronic phase CML and CML blast crisis [27, 67], and CLL $[27,29,38,39,68]$. In none of these studies was a prognostic significance of Pglycoprotein expression for response or survival detected. The results obtained so far for the lymphomas are not yet unequivocal. In one study [69] P-glycoprotein expression did not decrease the likelihood of response to induction chemotherapy. In another study [44] newly diagnosed and untreated lymphoma patients had a very low $(2 \%)$ incidence of P-glycoprotein expression, while previously treated and drug-resistant patients $(64 \%)$ had detectable levels of P-glycoprotein, suggesting that P-glycoprotein might contribute to drug resistance in lymphoma.

\section{Circumvention of drug resistance in leukaemias,} lymphomas and multiple myelomas

In clinical practice, the circumvention of drug resistance has been attempted by several approaches. The widespread use of polychemotherapy, in fact is based on the notion that as soon as the tumour becomes manifest in the patient, it already harbours a variety of drug-resistant cell clones as a conse- 
quence of spontaneous mutations. In the case of $\mathrm{P}$ glycoprotein-mediated MDR one may use alternative drugs which cannot serve as a substrate for the Pglycoprotein drug pump. However, often the number of active drugs is very limited; for example, in AML treatment the use of effective non-MDR drugs is limited to cytarabine. Dose escalation of the drugs in order to achieve higher intracellular drug concentrations has also been applied. However, that approach is hampered by a concurrent increase of toxicity, and, therefore, cannot be used without adequate stem cell support. In recent years, the attention has focused on the use of agents which inhibit the P-glycoprotein-mediated efflux of cytostatic drugs. With this approach promising results have been reported in pilot studies and phase I/II trials in MM. lymphoma and AML patients, in which MDR-related cytotoxic drugs were combined with RMAs. The clinical efficacy of the experimental protocols was assessed by the occurrence of otherwise unexpected tumour responses; a rather subjective criterion that must be regarded as such. Especially, two drugs (verapamil and cyclosporine $A$ ) have gained much attention as RMAs for classical MDR; verapamil, because it is the archetypal RMA, of which it was first demonstrated that it could overcome MDR in model systems [70], and cyclosporine $A$ due to its potency as a RMA [71,72] in relation to its low (reversible) toxicity profile at the desired plasma concentrations. Both drugs had the advantage of a long clinical history of use in other applications. Apart from the well-known drug-specific toxicities associated with high plasma concentrations, the combined use of RMAs and cytotoxic drugs did not lead to severe dysfunction of organs of which Pglycoprotein is a normal constituent, like liver, kidneys and colon.

In MM, verapamil has been added to VAD in VAD-refractory patients $[73,74]$. In these heavily pretreated patients some responses were noted. Verapamil was also used in the treatment of drug-refractory lymphoma [44] yielding an unexpected high percentage of CRs. The dose-limiting toxicity of the verapamil infusion was cardiac dysfunction including hypotension, congestive heart failure, and cardiac arrhythmia. In an excellent editorial, Chabner \& Wilson [75] discussed some specific problems with the interpretation of the clinical result, encountered in this kind of pilot study. The main problem in such studies is the clinical use of the term resistance, because patients with recurrent disease can respond to retreatment with their original regimen, especially in NHL. We reported the first clinical application of cyclosporine $A$ as a RMA, in a refractory AML patient [76]. In that case, the emergence of the classi- cal MDR phenotype was monitored during clinical progression of the disease. At relapse, a decrease in daunorubicin accumulation by AML blasts was associated with elevated P-glycoprotein expression and a decreased in vitro sensitivity to daunorubicin. Intracellular daunorubicin accumulation and in vitro sensitivity could be completely restored by adding cyclosporine $\mathrm{A}$ to the cells. During progressive relapse, the patient was treated with reinduction therapy to which cyclosporine A was added and this resulted in a transient elimination of the Pglycoprotein-positive AML clone. In France, a large $(n=16)$ study was carried out [77] in which relapsed $(n=7)$ or refractory $(n=9)$ acute leukaemias were treated with cyclosporine $A$ in combination with mitoxantrone and etoposide. This combination chemotherapy was effective in killing P-glycoproteinexpressing leukaemia cells and even two CRs were obtained. However, three of six respondents were Pglycoprotein-positive and the other three respondents P-glycoprotein-negative, obstructing a meaningful interpretation of the clinical responses. Other studies using cyclosporine $\mathrm{A}$ added to RI regimens in acute leukaemias with a poor prognosis are in progress. Using a similar approach, cyclosporine A was administered to VAD-refractory MM patients, leading to several unexpected lasting responses [78]. Before treatment, P-glycoprotein expression could be detected in the myeloma cells in some of the patients. However, after the experimental treatment, in four of six patients no P-glycoprotein-positive plasma cells were present, suggesting that cyclosporine plus VAD is effective against P-glycoproteinexpressing myeloma cells.

The dose-limiting toxicity of the cyclosporine infusion was musculoskeletal pain but also increased myelosuppression and hyperbilirubinaemia were noted. Hyperbilirubinaemia is a well-known sideeffect of cyclosporine $\mathrm{A}$ in transplantation studies, and now appears to occur also in the MDR-modulation studies [77-79]. The presence of P-glycoprotein on the luminal surfaces of the biliary tract [80] makes it likely that the increase in blood bilirubin during cyclosporine A treatment is due to impairment of the P-glycoprotein pump in the epithelial cells of the bile duct. Such an inhibition of the endogenous P-glycoprotein pump not only can lead to reduced bile excretion, but also to reduced biliary cytotoxic drug elimination, as has been shown for the MDRrelated drug colchicine [81]. In another animal study, the same authors [82] found that colchicine is actively secreted into the urine by P-glycoprotein in the proximal renal tubes and that the administration of cyclosporine A dramatically reduced renal clearance of colchicine. When these phenomena (impaired biliary 
and urinary drug excretion) also occur in patients (which is very likely), the combined use of cyclosporine $\mathrm{A}$ and cytotoxic drugs might contribute to altered pharmacokinetics, for example increased area under the plasma concentration/time curve (AUC) of the cytotoxic drugs, and a subsequent alteration in the toxicity profile [83-85]. In addition, pharmacokinetic changes in tissue distribution may also be induced by the possible haemodynamic effects of the RMAs themselves. Indeed, preclinical and clinical evidence is accumulating that significant pharmacokinetic interactions can take place upon the simultaneous use of RMAs and cytotoxic drugs [83, 86-89]. In patients, anthracycline peak levels, terminal half-life and the volume of distribution were higher, whereas plasma drug clearance and the volume of the central compartment were lower with coadministration of verapamil [86]. Nifedipine administered to vincristine-treated patients decreased vincristine clearance from the body [87]. In a phase I pharmacokinetic study, cyclosporine A produced a significant increase in VP-16 systemic exposure as a consequence of impaired total body clearance [89]. Altered pharmacokinetics (decreased total clearance, increased plasma AUC, and/or changes in tissue distribution) might, partly, explain why in clinical modulation studies often responses were seen too, in patients with drug resistant P-glycoproteinnegative tumours $[44,77,78]$.

Altogether, it seems very likely that in clinical use RMAs might have a specific, P-glycoproteinmediated effect on P-glycoprotein-expressing tumour cells as well as an aspecific, pharmacokineticmediated effect on both P-glycoprotein-positive and -negative tumour cells. New, less toxic and more potent RMAs, like the non-immunosuppressive cyclosporine analogue SDZ PSC 833 [72,90], are under phase I evaluation. The overall conclusion is that modulation of drug resistance by non-cytotoxic RMAs seems promising and needs further clinical evaluation in prospective, randomized phase III trials.

Acknowledgements-This work was supported by grants from the Dutch Cancer Society. Dr G. Stoter is thanked for helpful discussions and critical reading of the manuscript.

\section{References}

1. Roninson I. B. (1991) Molecular and Cellular Biology of Multidrug Resistance in Tumour Cells. Plenum Press, New York.

2. Schinkel A. H. \& Borst P. (1991) Multidrug resistance mediated by P-glycoproteins. Semin. Cancer Biol. 2, 213-226.
3. Liu L. F. (1989) DNA topoisomerase poisons as antitumour drugs. A. Rev. Biochem. 58, 351-357.

4. Beck W. T. \& Danks M. K. (1991) Mechanisms of resistance to drugs that inhibit DNA topoisomerases. Semin. Cancer Biol. 2, 235-244.

5. Potmesil M., Hsiang Y. H., Liu L. F., Bank B., Grossberg H., Kirschenbaum S., Forlenzar T. J., Penziner A., Kanganis D., Knowles D., Traganos F. \& Silber R. (1988) Resistance of human leukemic and normal lymphocytes to drug-induced DNA cleavage and low levels of DNA topoisomerase II. Cancer Res. 48, 3537-3543.

6. Gekeler V., Frese G., Noller A., Handgretinger R., Wilisch A., Schmidt H., Muller C. P., Dopfer R., Klingebiel T., Diddens H., Brobst H. \& Neithammer D. (1992) MDR1/P-glycoprotein, topoisomerase and glutathione-S-transferase pi gene expression in primary and relapse state adult and childhood leukaemias. $B r$. J. Cancer 66, 507-517.

7. McKenna S. L., Whittaker J. A., Padua R. A. \& Holmes J. A. (1993) Topoisomerase II expression in normal haemopoietic cells and chronic lymphocytic leukaemia: drug sensitivity or resistance. Leukemia 7, $1199-1203$.

8. Bhalla K., Hindenburg A., Taub R. N. \& Grant S. (1985) Isolation and characterization of an anthracycline-resistant human leukemic cell line. Cancer Res. 45, 3657-3662.

9. Slovak M. L., Hoeltge G. A., Dalton W. S. \& Trent J. M. (1988) Pharmacological and biological evidence for differing mechanisms of doxorubicin resistance in two human tumor cell lines. Cancer Res. 48, 27932797.

10. Baas F., Jongsma A. P. M., Broxterman H. J., Arceci R. J., Housman D., Scheffer G. L., Riethorst A., Groenigen M. van, Nieuwint A. W. M. \& Joenje H. (1990) Non-P-glycoprotein mediated mechanism for multidrug resistance precedes P-glycoprotein expression during in vitro selection for doxorubicin resistance in a human lung cancer cell line. Cancer Res. 50, 5392-5398.

11. Marquardt D. \& Center M. S. (1992) Drug transport mechanisms in HL60 cells isolated for resistance to adriamycin: evidence for nuclear drug accumulation and redistribution in resistant cells. Cancer Res. 52, 3157-3163.

12. Versantvoort C. H. M., Broxterman H. J., Pinedo H. M., Vries E. G. D. de, Feller N., Kuiper C. M. \& Lankelma J. (1992) Energy-dependent processes involved in reduced drug accumulation in multidrugresistant human lung cancer cell lines without P-glycoprotein expression. Cancer Res. 52, 7-23.

13. Versantvoort C. H. M., Broxterman H. J., Feller N., Dekker H., Kuiper C. M. \& Lankelma J. (1992) Probing daunorubicin accumulation defects in non-Pglycoprotein expressing multidrug-resistant cell lines using digitonin. Int. J. Cancer 50, 906-911.

14. Barrand M. A., Rhodes T., Center M. S. \& Twentyman P. R. (1993) Chemosensitisation and drug accumulation effects of cyclosporin A, PSC-833 and verapamil in human MDR large cell lung cancer cells expressing a $190 \mathrm{~K}$ membrane protein distinct from P-glycoprotein. Eur. J. Cancer 29A, 408-415.

15. Cole S. P. C., Bhardwaj G., Gerlach J. H., Mackie J. E., Grant C. E., Almquist K. C., Stewart A. J., Kruz E. U., Duncan A. M. V. \& Deeley R. G. (1992) 
Overexpression of a transporter gene in a multidrugresistant human lung cancer cell line. Science 258, 1650-1654.

16. Cole S. P. C. (1992) The 1991 Merck Frosst award. Multidrug resistance in small cell lung cancer. Can. J. Physiol. Pharmac. 70, 313-329.

17. Zaman G. J. R., Versantvoort C. H. M., Smit J. J. M., Eijdems E. W. H. M., Haas M. de, Smith A. J., Broxterman H. J., Mulder N. H., Vries E. G. E. de, Baas F. \& Borst P. (1993) Analysis of the expression of MRP, the gene for a new putative transmembrane drug transporter, in human multidrug resistant lung cancer cell lines. Cancer Res. 53, 1747-1750.

18. Nooter K. \& Herweijer H. (1991) Multidrug resistance $(m d r)$ genes in human cancer. Br. J. Cancer 63, 663669.

19. Roninson I. B., Chin J. E., Choi K., Gros P., Housman D. E., Fojo A., Shen D. W., Gottesman M. M. \& Pastan I. (1986) Isolation of human $m d r$ DNA sequences amplified in multidrug-resistant $\mathrm{KB}$ carcinoma cells. Proc. natn. Acad. Sci. U.S.A. 83, 45384542.

20. Bliek A. M. van der, Baas F., Houte-de Lange T. ten, Kooiman P. M., Velde-Koerts T. van der \& Borst P. (1987) The human $m d r 3$ gene encodes a novel Pglycoprotein homologue and gives rise to alternatively spliced mRNAs in liver. EMBO J. 6, 3325-3331.

21. Ueda K., Cardarelli C., Gottesman M. M. \& Pastan I. (1987) Expression of a full-length cDNA for the human ' $M D R I$ ' gene confers resistance to colchicine, doxorubicin, and vinblastine. Proc. natn. Acad. Sci. U.S.A. 84, 3004-3008.

22. Schinkel A. H., Roelofs M. E. M. \& Borst P. (1991) Characterization of the human $m d r 3$ P-glycoprotein and its recognitition by P-glycoprotein-specific monoconal antibodies. Cancer Res. 51, 2628-2635.

23. Gottesman M. M., Willingham M. C., Thiebaut F. \& Pastan I. (1991) Expression of the $M D R 1$ gene in normal human tissues. In Molecular and Cellular Biology of Multidrug Resistance in Tumor Cells (Roninson I. B., Ed.), pp. 279-289. Plenum Press, New York.

24. Akiyama S., Cornwell M. M., Kuwano M., Pastan I. \& Gottesman M. M. (1988) Most drugs that reverse multidrug resistance also inhibit photoaffinity labeling of P-glycoprotein by a vinblastine analog. Molec. Pharmac. 33, 144-147.

25. Herzog C. E., Trepel J. B., Mickley L. A., Bates S. E. \& Fojo A. T. (1992) Various methods of analysis of $\mathrm{mdr}-1 / \mathrm{P}$-glycoprotein in human colon cancer cell lines. J. Natl Cancer Inst. 84, 711-716.

26. Nooter K., Sonneveld P., Janssen A., Oostrum R., Boersma T., Herweijer H., Valerio D., Hagemeijer A. \& Baas F. (1990) Expression of the $m d r 3$ gene in prolymphocytic leukemia: association with cyclosporin-A-induced increase in drug-accumulation. Int. $J$. Cancer 45, 626-631.

27. Herweijer H., Sonneveld P., Baas F. \& Nooter K. (1990) Expression of $m d r 1$ and $m d r 3$ multidrugresistance genes in human acute and chronic leukemias and association with stimulation of drug accumulation by cyclosporine. J. Natl Cancer Inst. 82, 11331140.

28. Herweijer H., Nooter K., Beishuizen A., Sonneveld P., Oostrum R., Hesseling-Janssen A. L. W. \& Dongen J. van (1991) Expression of $m d r 1$ and $m d r 3$ multidrug- resistance genes in hairy cell leukaemia. Eur. J. Cancer 27, 297-298.

29. Sonneveld P., Nooter K., Burghouts J. Th. M., Herweijer H., Adriaanson H. J. \& Dongen J. J. M. van (1992) High expression of the mdr3 multidrug resistance gene in advanced stage chronic lymphocytic leukemia. Blood 70, 1496-1500.

30. Ma D. D. F., Davey R. A., Harman D. H., Isbister J. P., Scurr R. D., Mackertich S. M., Dowden G. \& Bell D. R. (1987) Detection of a multidrug resistant phenotype in acute non-lymphoblastic leukaemia. Lancet i, 135-137.

31. Bell D. R., Gerlach J. H., Kartner N., Buick R. N. \& Ling V. (1985) Detection of P-glycoprotein in ovarian cancer: a molecular marker associated with multidrug resistance. J. clin. Oncol. 3, 311-315.

32. Goldstein L. J., Galski H., Fojo A. T., Willingham M., Lai S. L., Gazdar A., Pirker R., Green A., Crist W., Brodeur G. M., Lieber M., Cossman J., Gottesman M. M. \& Pastan I. (1989) Expression of a multidrug resistance gene in human cancers. $J$. Natl Cancer Inst. 81, 116-124.

33. Holmes J., Jacobs A., Carter G., Janowska-Wieczorek A. \& Padua R. A. (1989) Multidrug resistance in haemopoietic cell lines, myelodysplastic syndromes and acute myeloblastic leukaemia. Br.J. Haemat. 72, $40-44$.

34. Nooter K., Sonneveld P., Oostrum R., Herweijer H., Hagenbeek A. \& Valerio D. (1990) Overexpression of the $m d r 1$ gene in blast cells from patients with acute myelocytic leukemia is associated with decreased anthracycline accumulation that can be restored by cyclosporin-A. Int. J. Cancer 45, 263-268.

35. Rothenberg M. L., Mickley L. A., Cole D. E., Balis F. M., Tsuruo T., Poplack D. G. \& Fojo A. T. (1989) Expression of the $m d r-1 / \mathrm{P}-170$ gene in patients with acute lymphoblastic leukemia. Blood 74, 1388-1395.

36. Goasguen J. E., Dossot J. M., Fardel O., Le Mee F., Le Gall E., Leblay R., Leprise P. Y., Chaperon J. \& Fauchet R. (1993) Expression of the multidrug resistance-associated P-glycoprotein (P-170) in 59 cases of de novo acute lymphoblastic leukemia: prognostic implications. Blood 81, 2394-2398.

37. Tsuruo T., Sugimoto Y., Hamada H., Roninson I., Okumura M., Adachi K., Morishima Y. \& Ohno R. (1987) Detection of multidrug resistance markers, $\mathrm{P}$ glycoprotein and $m d r 1$ mRNA, in human leukemia cells. Jpn. J. Cancer Res. (Gann) 78, 1415-1419.

38. Holmes J. A., Jacobs A., Carter G., Whittaker J. A., Bentley D. P. \& Padua R. A. (1990) Is the $m d r l$ gene relevant in chronic lymphocytic leukemia? Leukemia 4, 216-218.

39. Shustik C., Groulx N. \& Gros P. (1991) Analysis of multidrug resistance (MDR-1) gene expression in chronic lymphocytic leukaemia (CLL). Br. J. Haemat. 79, 50-56.

40. Dalton W. S., Grogan T. M., Rybski J. A., Scheper R. J., Richter L., Kailey J., Broxterman H. J., Pinedo H. M. \& Salmon S. E. (1989) Immunohistochemical detection and quantitation of P-glycoprotein in multiple drug-resistant human myeloma cells: association with level of drug resistance and drug accumulation. Blood 73, 747-752.

41. Epstein J., Xiao H. \& Oba B. K. (1989) P-glycoprotein expression in plasma-cell myeloma is associated with resistance to VAD. Blood 74, 913-917. 
42. Linsenmeyer M. E., Jefferson S., Wolf M., Matthews J. P., Board P. G. \& Woodcock D. M. (1992) Levels of expression of the $m d r l$ gene and glutathione Stransferase genes 2 and 3 and response to chemotherapy in multiple myeloma. $B r$. J. Cancer 65, 471475.

43. Moscow J. A., Fairchild C. R., Madden M. J., Ransom D. T., Wieand H. S., O'Brien E. E., Poplack D. G., Cossman J., Myers C. \& Cowan K. H. (1989) Expression of anionic glutathione-S-transferase and $\mathrm{P}$ glycoprotein genes in human tissues and tumors. Cancer Res. 49, 1422-1428.

44. Miller T. P., Grogan T. M., Dalton W. S., Spier C. M., Scheper R. J. \& Salmon S. E. (1991) P-glycoprotein expression in malignant lymphoma and reversal of clinical drug resistance with chemotherapy plus highdose verapamil. J. clin. Oncol. 9, 17-24.

45. Pileri S. A., Sabattini E., Falini B., Tazzari P. L., Gherlinzoni F., Michieli M. G., Damiani D., Zuccini L., Gobbi M., Tsuruo T. \& Baccarani M. (1991) Immunohistochemical detection of the multidrug transport protein $\mathrm{P} 170$ in human normal tissues and malignant lymphomas. Histopathology 91, 131-140.

46. Sato H., Preisler H., Day R., Raza A., Larson R., Browman G., Goldberg J., Vogler R., Grunwald H., Gottlieb A., Bennett J., Gottesman M. \& Pastan I. (1990) MDR1 transcript levels as an indication of resistant disease in acute myelogenous leukaemia. $\mathrm{Br} . J$. Haemat. 75, 340-345.

47. Marie J. P., Zittoun R. \& Sikic B. I. (1991) Multidrug resistance ( $m d r l)$ gene expression in adult acute leukemias: correlations with treatment outcome and in vitro drug sensitivity. Blood 78, 586-592.

48. Zhou D. C., Marie J. P., Suberville A. M. \& Zittoun R. (1992) Relevance of $m d r l$ gene expression in acute myeloid leukemia and comparison of different diagnostic methods. Leukemia 6, 879-885.

49. Grogan T. M., Spier C. M., Salmon S. E., Matzner M., Rybski J., Weinstein R. S., Scheper R. J. \& Dalton W. S. (1993) P-glycoprotein expression in human plasma cell myeloma: correlation with prior chemotherapy. Blood 81, 490-495.

50. Kohno K., Sato S., Takano H., Matsuo K. \& Kuwano M. (1989) The direct activation of human multidrug resistance gene ( $m d r l)$ by anticancer agents. Biochem. biophys. Res. Commun. 165, 1415-1421.

51. Chin K. V., Tanaka S., Darlington G., Pastan I. \& Gottesman M. M. (1990) Heat shock and arsenite increase expression of the multidrug resistance (MDR1) gene in human renal carcinoma cells. J. biol. Chem. 265, 221-226.

52. Tanimura H., Kohno K., Sato S., Uchiumi T., Miyazaki M., Kobayashi M. \& Kuwano M. (1992) The human multidrug resistance 1 promoter has an element that responds to serum starvation. Biochem. biophys. Res. Commun. 183, 917-924.

53. Chaudhary P. M. \& Roninson I. B. (1991) Expression and activity of $P$-glycoprotein, a multidrug efflux pump, in human hematopoietic stem cells. Cell 66, 85-94.

54. Drach D., Zhao S., Drach J., Mahadevia R., Gattringer C., Huber H. \& Andreeff M. (1992) Subpopulations of normal peripheral blood and bone marrow cells express a functional multidrug resistant phenotype. Blood 80, 2729-2734.

55. Gruber A., Vitols S., Norgren S., Arestrom I., Peterson C., Bjorkholm M., Reizenstein P. \& Luthman
H. (1992) Quantitative determination of $m d r l$ gene expression in leukaemic cells from patients with acute leukaemia. Br. J. Cancer 66, 266-272.

56. List A. F., Spier C. M., Cline A., Doll D. C., Garewal H., Morgan R. \& Sandberg A. A. (1991) Expression of the multidrug resistance gene product (P-glycoprotein) in myelodysplasia is associated with a stem cell phenotype. Br. J. Haemat. 78, 28-34.

57. Campos L., Guyotat D., Archimbaud E., CalmardOriol P., Tsuruo T., Troncy J., Treille D. \& Fiere D. (1992) Clinical significance of multidrug resistance Pglycoprotein expression on acute nonlymphoblastic leukemia cells at diagnosis. Blood 79, 473-476.

58. Sonneveld P., Dongen J. J. M. van, Hagemeijer A., Lom K. van, Nooter K., Schoester M., Adriaansen H. J., Tsuruo T. \& De Leeuw K. (1993) High expression of the multidrug resistance $\mathrm{P}$-glycoprotein in high risk myelodysplasia is associated with immature phenotype. Leukemia 7, 963-969.

59. Chin K. V., Ueda K., Pastan I. \& Gottesman M. M. (1992) Modulation of activity of the promoter of the human $m d r l$ gene by ras and p53. Science $\mathbf{2 5 5}, 459$ 462.

60. Kuwazuru Y., Yoshimura A., Hanada S., Utsunomiya A., Makino T., Ishibashi K., Kodama M., Iwahashi M., Arima T. \& Akiyama S. I. (1990) Expression of the multidrug transporter, P-glycoprotein, in acute leukemia cells and correlation to clinical drug resistance. Cancer 66, 868-873.

61. Pirker R., Wallner J., Geissler K., Linkesch W., Haas O. A., Bettelheim P., Hopfner M., Scherrer R., Valent P., Havelec L., Ludwig H. \& Lechner K. (1991) $m d r 1$ gene expression and treatment outcome in acute myeloid leukaemia. J. Natl. Cancer Inst. 83, 708-712.

62. Te Boekhorst P. A. W., Wittebol S., Hagemeijer A., Lowenberg B., Nooter K. \& Sonneveld P. (1993) Predominance of the multidrug resistance phenotype in acute myeloid leukemia cells is associated with an immature (CD34) phenotype. Blood 82, 3157-3162.

63. Dulik D. M., Feuselau C. \& Hilton J. (1986) Characterization of melphalan-glutathione adducts whose formation is catalysed by glutathione transferase. Biochem. Pharmac. 35, 3405-3411.

64. Sonneveld P., Durie B. G. M., Lokhorst H. M., Frutiger Y., Schoester M. \& Vela E. E. (1993) Analysis of multidrug-resistance (MDR-1) glycoprotein and CD56 expression to separate monoclonal gammopathy from multiple myeloma. Br. J. Haemat. 83, 63-67.

65. Cornelissen J. J., Sonneveld P., Dekker A. W., Schoester M. \& Lokhorst H. M. (1993) MDR-1 expression and response to VAD chemotherapy in multiple myeloma. J. clin. Oncol. (in press).

66. Musto P., Melillo L., Lombardi G., Matera R., Di Giorgio G. \& Carotenuto M. (1991) High risk of early resistant relapse for leukaemia patients with presence of multidrug resistance associated P-glycoprotein positive cells in complete remission. Br. J. Haemat. 77, 5053.

67. Weide R., Dowding C., Paulsen W. \& Goldman J. (1990) The role of the MDR-1/P-170 mechanism in the development of multidrug resistance in chronic myeloid leukemia. Leukemia 4, 695-699.

68. Cumber P. M., Jacobs A., Hoy T., Fischer J., Whittaker J. A., Tsuruo T. \& Padua R. A. (1990) Expression of the multiple drug resistance gene ( $m d r$ - 
1) and epitope masking in chronic lymphatic leukaemia. Br. J. Haemat. 76, 226-230.

69. Niehans G. A., Jaszsz W. Q., Brunetto V., Perri R. T., Gajl-Peczalska K., Wick M. R., Tsuruo T. \& Bloomfield C. (1992) Immunohistochemical identification of P-glycoprotein in previously untreated, diffuse large cell and immunoblastic lymphomas. Cancer Res. 52, 3768-3775.

70. Tsuruo T., Iida H., Tsukagoshi S. \& Sakurai Y. (1981) Overcoming of vincristine resistance in P388 leukemia in vivo and in vitro through enhanced cytotoxicity of vincrinstine and vinblastine by verapamil. Cancer Res. 41, 1967-1972.

71. Nooter K., Oostrum R., Jonker R., Dekken H. van, Stokdijk W. \& Engh G. van den, (1989) Effect of cyclosporin $A$ on daunorubicin accumulation in multidrug-resistant P388 leukemia cells measured by realtime flow cytometry. Cancer Chemother. Pharmac. 23, 296-300.

72. Twentyman P. R. (1992) Cyclosporins as drug resistance modifiers. Biochem. Biopharmac. 43, 109-117.

73. Durie B. G. M. \& Dalton W. S. (1988) Reversal of drug-resistance in multiple myeloma with verapamil. Br. J. Haemat. 68, 203-206.

74. Salmon S. E., Dalton W. S., Grogan T. M., Plezia P., Lehnert M., Roe D. J. \& Miller T.P. (1991) Multidrugresistant myeloma: laboratory and clinical effects of verapamil as a chemosensitizer. Blood 78, 44-50.

75. Chabner B. A. \& Wilson W. (1991) Reversal of multidrug resistance. $J$. clin. Oncol. 9, 4-6.

76. Sonneveld P. \& Nooter K. (1990) Reversal of drugresistance by cyclosporin-A in a patient with acute myelocytic leukaemia. Br. J. Haemat. 75, 208-211.

77. Marie J. P., Bastie J. N., Coloma F., Suberville A. M., Delmer A., Rio B., Delmas-Marsalet B., Leroux G., Casassus P., Baumelou E., Catalin J. \& Zittoun R. (1993) Cyclosporin A as a modifier agent in the salvage treatment of acute leukemia (AL). Leukemia 7, 821-824.

78. Sonneveld P., Durie B. G. M., Lokhorst H. M., Marie J. P., Solbu G., Suciu S., Zittoun R., Lowenberg B. \& Nooter K. (1992) Modulation of multidrug resistant multiple myeloma by cyclosporin. Lancet 340, 255259.

79. Yahanda A. M., Adler K. M., Fischer G. A., Brophy N. A., Halsey R., Hardy R. I., Gosland M. P., Lum B. L. \& Sikic B. I. (1992) Phase I trial of etoposide with cyclosporine as a modulator of multidrug resistance. $J$. clin. Oncol. 10, 1624-1634.

80. Valk P. van der, Kalken C. K. van, Ketelaars H.,
Broxterman H. J., Scheffer G., Kuiper C. M., Tsuruo T., Lankelma J., Meijer C. J. L. M., Pinedo H. M. \& Scheper R. J. (1990) Distribution of multi-drug resistance-associated P-glycoprotein in normal and neoplastic human tissues. Ann. Oncol. 1, 56-64.

81. Speeg K. V., Maldonado A. L., Liaci J. \& Muirhead D. (1992) Effect of cyclosporine on colchicine secretion by a liver canalicular transporter studied in vivo. Hepatology 15, 899-903.

82. Speeg K. V., Maldonado A. L., Liaci J. \& Muirhead D. (1992) Effect of cyclosporine on colchicine secretion by the kidney multidrug transporter studied in vivo. $J$. Pharmac. exp. Ther. 261, 50-55.

83. Nooter K., Oostrum R. \& Deurloo J. (1987) Effects of verapamil on the pharmacokinetics of daunomycin in the rat. Cancer Chemother. Pharmac. 20, 176-178.

84. Stephens L. C., Wang Y M., Schultheiss T. E. \& Jardine J. H. (1987) Enhanced cardiotoxicity in rabbits treated with verapamil and adriamycin. Oncology 44, 302-305.

85. Bright J. M. \& Buss D. D. (1990) Effects of verapamil on chronic doxorubicin-induced cardiotoxicity in dogs. J. Natl Cancer Inst. 82, 963-964.

86. Kerr D. J., Graham J., Cummings J., Morrison J. G., Thompson G. G., Brodie M. J. \& Kaye S. B. (1986) The effect of verapamil on the pharmacokinetics of adriamycin. Cancer Chemother. Pharmac. 18, 239-242.

87. Fedeli L., Colozza M., Boschetti E., Sabalich I., Aristei C., Guerciolini R., Del Favero A., Rossetti R., Tonato M., Rambotti P. \& Davis S. (1989) Pharmacokinetics of vincristine in cancer patients treated with nifedipine. Cancer 64, 1805-1811.

88. Keller R. P., Altermatt H. J., Donatsch P., Zihlmann H., Laissue J. A. \& Hiestand P. C. (1992) Pharmacologic interactions between the resistance-modifying cyclosporine SDZ PSC 833 and etoposide (VP 16-213) enhance in vivo cytostatic activity and toxicity. Int. J. Cancer 51, 433-438.

89. Lum B. L., Kaubisch S., Yahanda A. M., Adler K. M., Jew L., Ehsan M. N., Brophy N. A., Halsey J., Gosland M. P. \& Sikic B. I. (1992) Alteration of etoposide pharmacokinetics and pharmacodynamics by cyclosporine in a phase I trial to modulate multidrug resistance. $J$. clin. Oncol. 10, 1635-1642.

90. Te Boekhorst P. A. W., Kapel J. van, Schoester M. \& Sonneveld P. (1992) Reversal of typical multidrug resistance by cyclosporin and its non-immunosuppressive analogue SDZ PSC 833 in Chinese hamster ovary cells expressing the $m d r l$ phenotype. Cancer Chemother. Pharmac. 30, 238-242. 